\title{
Effects of octreotide on responses to colorectal distension in the rat
}

\author{
X Su, M B Burton, G F Gebhart
}

\begin{abstract}
Background and aims-It has been suggested that the analgesic effect of the somatostatin analogue octreotide in visceral pain involves peripheral mechanisms. We evaluated the effect of octreotide on responses to noxious colorectal distension in rats.

Methods-In a behavioural study, pressor and electromyographic responses to colorectal distension were evaluated before and after intravenous or intrathecal administration of octreotide. In pelvic nerve afferent fibre recordings, responses of mechanosensitive fibres innervating the colon to noxious colorectal distension ( 80 $\mathrm{mm} \mathrm{Hg}$, 30 seconds) were tested before and after octreotide.

Results-Octreotide was ineffective in attenuating responses to colorectal distension in either normal or acetic acid inflamed colon when administered intravenously but attenuated responses when given intrathecally. Administration of octreotide over a broad dose range $(0.5 \mu \mathrm{g} / \mathrm{kg}$ to $2.4 \mathrm{mg} / \mathrm{kg}$ ) did not alter responses of afferent fibres to noxious colorectal distension in untreated, or acetic acid or zymosan treated colons.

Conclusions-In the rat, octreotide has no peripheral (pelvic nerve) modulatory action in visceral nociception. The antinociceptive effect of octreotide in this model of visceral nociception is mediated by an action at central sites.

(Gut 2001;48:676-682)
\end{abstract}

Department of

Pharmacology, Bowen

Science Building,

College of Medicine

University of Iowa,

Iowa City, Iowa 52242,

USA

$\mathrm{X} \mathrm{Su}$

M B Burton†

G F Gebhart

†Present address:

Department of Biochemistry and Medical Biology,

University of South Dakota,

414E Clark Street,

Vermillion, SD 57069, USA

Correspondence to:

Dr G F Gebhart,

Department of

Pharmacology, Bowen

Science Building, University

of Iowa, Iowa City, IA

52242-1109, USA

gf-gebhart@uiowa.edu

Accepted for publication 5 December 2000
Keywords: octreotide; colorectal distension; pain; analgesic effect; rat

Discomfort and pain are common complaints of patients suffering from a functional bowel disorder such as irritable bowel syndrome (IBS). Treatment strategies for symptom management in IBS are varied and largely unsuccessful. ${ }^{1}$ Several clinical studies however suggest that the somatostatin analogue octreotide can attenuate discomfort and pain produced by balloon distension of the colon in both normal subjects ${ }^{23}$ and IBS patients. ${ }^{45}$

The site(s) and mechanism(s) of action of octreotide are unknown. Somatostatin and its receptors have been detected in the peripheral nervous system ${ }^{6-9}$ and somatostatin has been reported to inhibit afferent fibres innervating the rat knee joint. ${ }^{10}$ There is no direct evidence supporting inhibition of visceral afferent fibres by octreotide, although this site of action was electromyographic responses; afferent fibres; visceral suggested by several authors. ${ }^{211}$ Accordingly, one aim of this study was to test the peripheral actions of octreotide in a rat model of visceral nociception. Because inflammatory mediators in peripheral tissue may alter processing of sensory information, the action of octreotide in acute colonic inflammation was also tested.

Evidence also exists for central sites of analgesic action of octreotide. In several clinical reports, spinal infusion of octreotide was found to provide relief of pain. ${ }^{12}{ }^{13}$ In support, Chrubasik and colleague ${ }^{14}$ reported that intrathecal somatostatin-14 reduced pain in a series of cancer patients. Somatostatin is localised in primary afferent fibre terminals in the superficial spinal dorsal horn ${ }^{6}{ }^{15}$ and spinal application of somatostatin depresses nociceptive dorsal horn neurones. ${ }^{16}$ Accordingly, a second aim of this study was to evaluate a spinal site of action of octreotide in visceral nociception.

\section{Materials and methods}

Male Sprague-Dawley rats weighing 340-580 g (Harlan, Indianapolis, Indiana, USA) were anaesthetised with sodium pentobarbital (40-45 $\mathrm{mg} / \mathrm{kg}$ intraperitoneally; Nembutal, Abbott Laboratories, North Chicago, Illinois, USA). A femoral artery and vein were catheterised for measurement of arterial pressure and administration of sodium pentobarbital or drug, respectively. At the end of behavioural and electrophysiological experiments (see below), rats were killed by an overdose of intravenous pentobarbital. The experimental protocol was approved by the Institutional Animal Care and Use Committee of the University of Iowa.

\section{BEHAVIOURAL STUDY}

Teflon coated stainless steel wire electrodes (Cooner Wires, Chatworth, California, USA) were stitched into the external oblique musculature immediately superior to the inguinal ligament for electromyographic (EMG) recording. Arterial and venous catheters and EMG electrodes were tunnelled subcutaneously and externalised at the back of the neck. In some experiments, an intrathecal catheter (PE10, $8.5 \mathrm{~cm}$ ) was extended to the lumbar enlargement through a slit in the atlantooccipital membrane. The intrathecal catheter was externalised at the back of the neck together with the arterial catheter and EMG

Abbreviations used in this paper: IBS, irritable bowel syndrome; CRD, colorectal distension; EMG, electromyogram; MAP, mean arterial pressure; VMR, visceromotor response; HAc, acetic acid; SRFs, stimulus-response functions; SSTR, somatostatin receptor. 
electrodes in these experiments. After recovery from anaesthesia, rats were housed separately for at least three days prior to testing.

For colorectal distension (CRD), a 6-7 cm long, $2-3 \mathrm{~cm}$ diameter balloon was inserted intra-anally into the descending colon and rectum. The balloon catheter was connected to a distension control device (Biomedical Engineering, University of Iowa, Iowa City, Iowa, USA) via a low volume pressure transducer and intracolonic pressure was continuously monitored (see Gebhart and Sengupta ${ }^{17}$ for details). CRD in awake rats results in two readily quantifiable pseudaffective (that is, spinobulbospinal) responses ${ }^{18}$ : an increase in mean arterial pressure (MAP) and contraction of the abdominal and hindlimb musculature, termed the visceromotor response (VMR). VMR was quantified by measuring EMG activity in the external oblique musculature. The arterial catheter was connected to a low volume pressure transducer (Cobe Labs, Linkwood, Colorado, USA) and the EMG signal was amplified $(\times 10000,300-1000 \mathrm{~Hz})$ and filtered $(200 \mathrm{~Hz}$ high pass, 4 pole Butterworth; graphic equaliser, Yamaha). Distending pressure, arterial pressure, and EMG were digitised at $1000 \mathrm{~Hz}$ (DT280, Data Translation, Marlboro, Massachusetts, USA) and processed using programs written in ASYST. The EMG signal was rectified and averaged over $500 \mathrm{~ms}$, reducing the effective sampling to $2 \mathrm{~Hz}$. All signals were viewed on line and also recorded for subsequent analysis.

Staircase distension was used for CRD. ${ }^{19}$ Briefly, starting at $0 \mathrm{~mm} \mathrm{Hg}$, intracolonic pressure was incremented in steps $(10-20 \mathrm{~mm} \mathrm{Hg}$ ) over about 80 seconds to a final pressure of $80 \mathrm{~mm} \mathrm{Hg}$. Changes in MAP and EMG were quantified during the initial five seconds of each distension step. Three to five staircase distensions, at four minute intervals, were given six hours after intracolonic instillation of either saline or $1 \mathrm{ml}$ of $5 \%$ acetic acid (HAc) ${ }^{20}$ to establish predrug baseline response magnitude and threshold. Octreotide was then administered intravenously or intrathecally using a single dose or cumulative dosing paradigm; two staircase distensions were given four and eight minutes after drug administration, followed by the next dose of drug (intrathecal study).

SINGLE FIBRE RECORDING

The trachea was cannulated to allow artificial ventilation with room air. For intra-arterial drug administration, a catheter was passed into the descending aorta via the left common carotid artery. Mean arterial blood pressure was monitored continuously and maintained $>80 \mathrm{~mm} \mathrm{Hg}$ with intravenous $5 \%$ dextrose in saline given in a bolus of $1-1.5 \mathrm{ml}$ as required. The lower abdomen was exposed by a $3-4 \mathrm{~cm}$ long incision laterally at the left flank. The pelvic nerve was isolated from surrounding tissues and wrapped with a pair of Teflon coated stainless steel wires stripped at the tips and sealed with non-reactive Wacker gel (Wacker Silicone Corp., Adrian, MI, USA). The spinal cord was exposed by laminectomy (T13-S2) and covered with warm $\left(37^{\circ} \mathrm{C}\right)$ mineral oil. Recordings were made from the distal cut end of pelvic nerve afferent fibres in the S1 dorsal root. The dorsal rootlet was split into fine filaments to obtain a single unit. Electrical activity of the single unit was recorded by a monopolar silver-silver chloride electrode. Action potentials were monitored continuously by analogue delay and displayed on a storage oscilloscope after initial amplification through a low noise AC differential amplifier. Action potentials were processed through a window discriminator and counted (one second binwidth) using the spike2/CED 1401 data acquisition program. Peristimulus time histograms, intracolonic pressure, and blood pressure were displayed on line continuously. All parameters were also recorded for off line analysis.

Pelvic nerve input to the $\mathrm{S} 1$ dorsal root was identified first by electrical stimulation of the pelvic nerve (single $0.5 \mathrm{~ms}$ square wave pulse at 3-8 $\mathrm{mV}$ ). Fibres were classified on the basis of their conduction velocities; those with conduction velocities $<2.5 \mathrm{~m} / \mathrm{s}$ were considered unmyelinated $\mathrm{C}$ fibres and those with conduction velocities $>2.5 \mathrm{~m} / \mathrm{s}$ were considered thinly myelinated $\mathrm{A} \delta$ fibres. If a fibre responded to CRD, responses to phasic distending pressures of $5,10,20,30,40,60,80$, and $100 \mathrm{~mm} \mathrm{Hg}, 30$ seconds at four minute intervals, were determined; a noxious intensity of CRD $(80 \mathrm{~mm}$ $\mathrm{Hg}, 30$ seconds) was used thereafter in these experiments.

For acute inflammation of the colon, the balloon was removed and $1.5-2 \mathrm{ml}$ of $5 \%$ HAc in saline was instilled intra-anally into the descending colon. The irritant was held in the colon for 15 minutes, the colon was flushed with warm saline, and the balloon reinserted. Other rats received identical treatment with vehicle (saline). In three rats, the balloon was removed and zymosan $(25 \mathrm{mg} / \mathrm{ml}, 2 \mathrm{ml}$ in $30 \%$ ethanol) was instilled into the colon as a second model of sensitisation of responses to CRD. ${ }^{21}$ The balloon was reinserted and responses to $80 \mathrm{~mm} \mathrm{Hg} \mathrm{CRD} \mathrm{were} \mathrm{studied} 30$ minutes after intracolonic treatment.

The effects of octreotide were tested on responses of mechanosensitive afferent fibres to $80 \mathrm{~mm} \mathrm{Hg}$ CRD. Octreotide was administered intra-arterially or intravenously using a cumulative dose paradigm. Each dose of drug was given 90 seconds before the onset of distension. Drugs were tested on responses of fibres recorded from untreated and HAc or zymosan treated colons. As a positive control, the kappa opioid receptor agonist U50,488, which attenuates responses of pelvic nerve afferent fibres to noxious distension, ${ }^{22}{ }^{23}$ was tested in two experiments after octreotide had been tested.

\section{DATA ANALYSIS}

Differences between resting EMG activity and MAP before and after drug administration were compared using a non-parametric Wilcoxon test to determine whether there were changes in these parameters attributable to drug action. Dose-response relationships were constructed to show dose dependent changes 

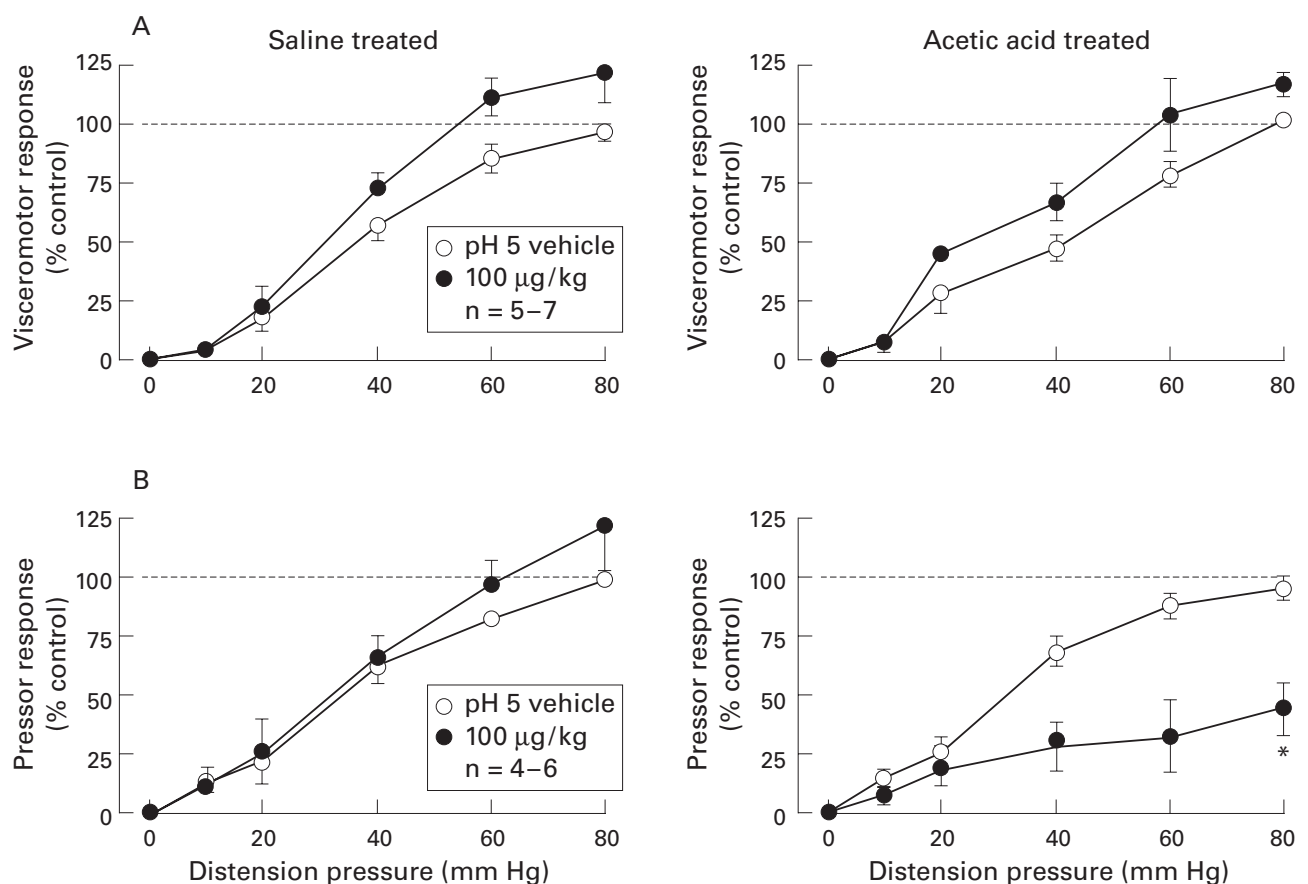

Figure 1 Stimulus-response functions (SRFs) for visceromotor $(A)$ and pressor $(B)$ responses to colorectal distension before (vehicle) and after intravenous administration of octreotide $(100 \mu \mathrm{g})$ in saline and acetic acid treated rats. The broken line represents the control response to $80 \mathrm{~mm} \mathrm{Hg}$ distension as $100 \%$. All data are expressed as percentage of maximal control response (mean (SEM)). The basis for $n$ is the number of rats used in constructing each SRF. *Significantly different from control group (ANOVA).

in response magnitudes at innocuous $(20 \mathrm{~mm}$ $\mathrm{Hg}$ ) and noxious $(60 \mathrm{~mm} \mathrm{Hg})$ intensities of distension.

The resting activity of an afferent fibre was counted for 60 seconds before CRD and the response to distension was determined as the increase in discharge during distension above its resting activity. Results were analysed using analysis of variance (ANOVA) for repeated measures.
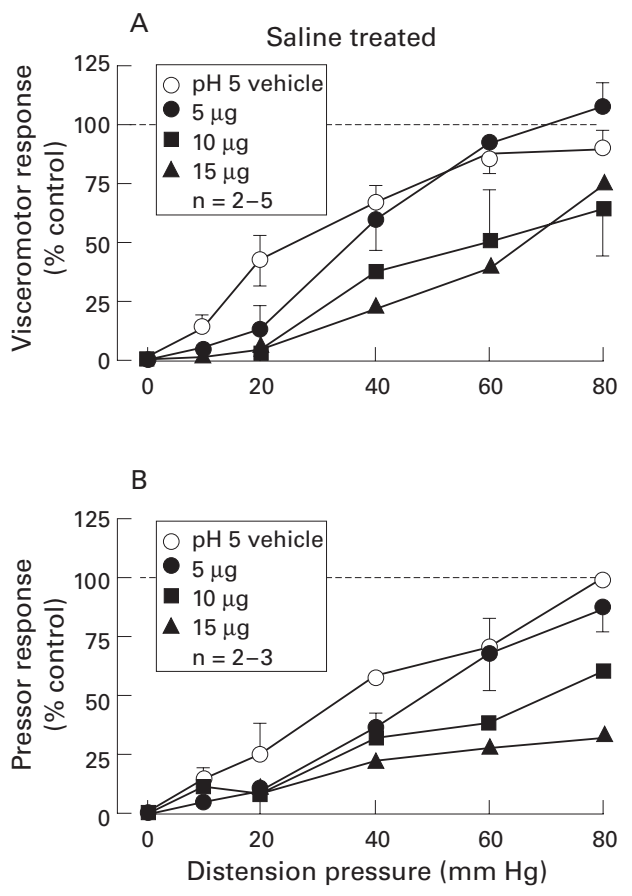

All data are expressed as mean (SEM). A value of $p<0.05$ was considered statistically significant.

DRUGS

Commercially available octreotide acetate (Sandostation; Sandoz Pharmaceutical Co., East Hanover, New Jersey, USA) was used throughout. Octreotide is a cyclic octapeptide; the acetate salt has a molecular weight of

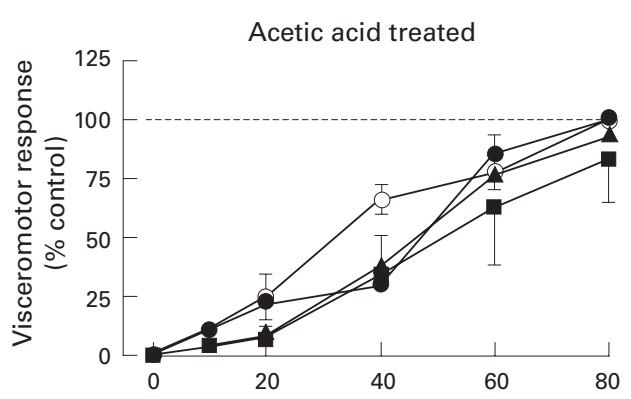

Figure 2 Stimulus response functions ( $S R F$ s) for visceromotor $(A)$ and pressor $(B)$ responses to colorectal distension (CRD) before (vehicle) and after cumulative doses of intrathecal administration of octreotide (5-15 $\mu \mathrm{g})$ in saline and acetic acid treated rats. The broken line represents the control response to $80 \mathrm{~mm} \mathrm{Hg}$ distension as $100 \%$. All data are expressed as percentage of control response (mean (SEM)). The basis for $n$ is the number of rats used in constructing each SRF. Intrathecal octreotide dose dependently attenuated the visceromotor $(A)$ and pressor (B) responses to $C R D$ in saline treated rats. 

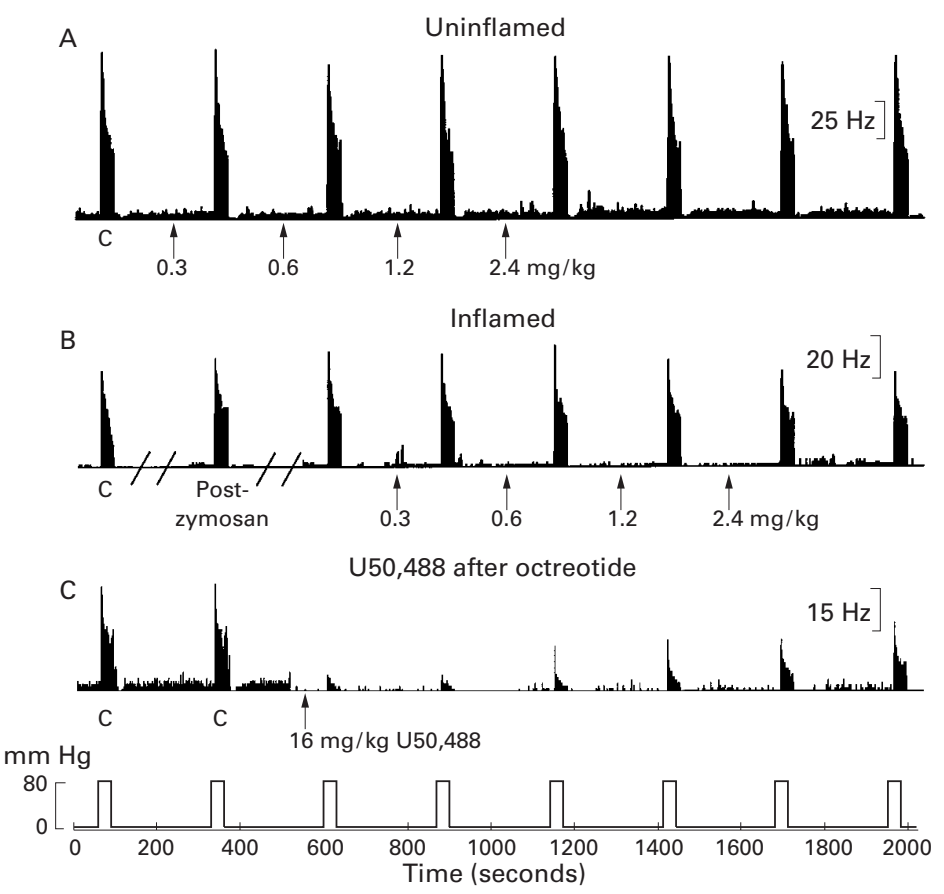

Figure 3 Effects of cumulative systemic administration of octreotide on responses of pelvic nerve afferent fibres to noxious colorectal distension (CRD) ( $80 \mathrm{~mm} \mathrm{Hg}, 30$ seconds). Examples of lack of effect of octreotide on responses of different $A \delta$ afferent fibres to CRD in uninflamed colon $(A)$ and zymosan inflamed colon $(B)$. Thirty minutes after intracolonic injection of zymosan ( $25 \mathrm{mg} / \mathrm{ml}, 2 \mathrm{ml}$ in $30 \%$ ethanol), the fibre in (B) was sensitised (response magnitude increased from $679 \mathrm{imp} / 30$ s to $897 \mathrm{imp} / 30 \mathrm{~s}$, an increase to $132 \%$ of the pre-zymosan control (" $C$ ") response). Octreotide was injected intra-arterially in a cumulative dose as indicated by the arrows. Responses of the fibres are illustrated as peristimulus time histograms (one second binwidth); distending pressure ( $80 \mathrm{~mm} \mathrm{Hg}, 30$ seconds every four minutes) is presented below. In (C), the effect of U50,488 (16 mg/kg) is shown for a fibre that had previously received cumulative doses of octreotide $(2.4 \mathrm{mg} / \mathrm{kg})$.
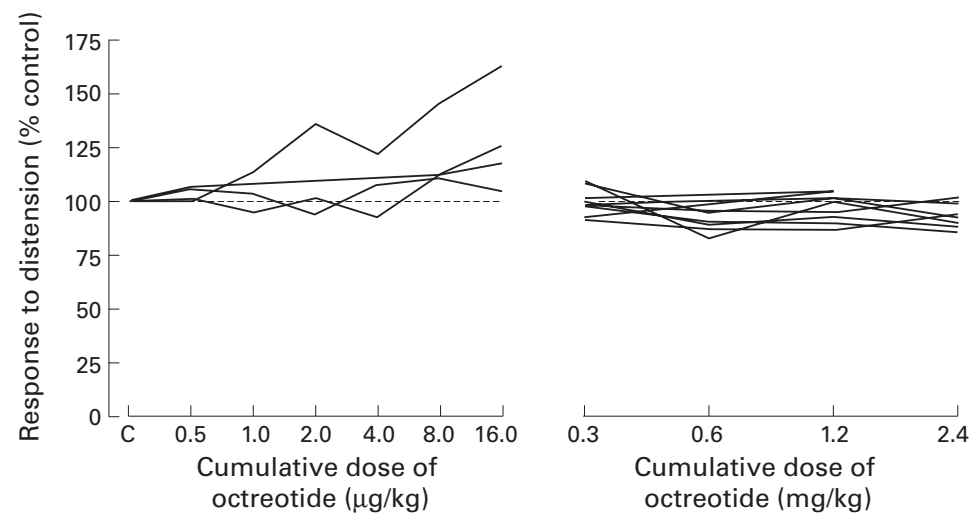

Figure 4 Absence of dose dependent effects of octreotide on responses of individual pelvic nerve afferent fibres to noxious colorectal distension ( $80 \mathrm{~mm} \mathrm{Hg}$, 30 seconds, as percentage of control). Octreotide failed to attenuate responses of pelvic nerve afferent fibres recorded from either untreated or zymosan treated colon.

1019.3. U50,488 (molecular weight 465.4) was purchased from Research Biochemicals Inc. (Natick, Massachusetts, USA). Zymosan was purchased from Sigma Chemical Co., (St Louis, Missouri, USA).

\section{Results}

BEHAVIOURAL STUDY

All rats exhibited monotonic increases in visceromotor and pressor responses to graded intensities of CRD $(10-80 \mathrm{~mm} \mathrm{Hg}, 20$ seconds) (figs 1,2). The mean maximal pressor responses to $80 \mathrm{~mm} \mathrm{Hg} \mathrm{CRD}$ did not differ between rats treated intracolonically six hours earlier with saline (21 (3) $\mathrm{mm} \mathrm{Hg}$ ) or $5 \% \mathrm{HAc}$
(18 (2) $\mathrm{mm} \mathrm{Hg}$ ), consistent with previous results in this model. ${ }^{20}$ Response magnitudes for VMR at $80 \mathrm{~mm} \mathrm{Hg} \mathrm{CRD} \mathrm{were} 150$ (10.6)\% and $249(21) \%$ of control in saline and HAc treated rats $(\mathrm{p}<0.05)$, respectively, revealing an enhanced response to a noxious intensity of distension (that is, hyperalgesia). ${ }^{20}$ There were no changes in response threshold.

When given intravenously, the single dose of octreotide tested $(100 \mu \mathrm{g} / \mathrm{kg})$ had no effect on VMR in saline or HAc treated rats (fig 1). However, octreotide significantly attenuated the increase in MAP in response to CRD but only in HAc treated rats (fig 1). The mean maximal pressor response to $80 \mathrm{~mm} \mathrm{Hg} \mathrm{CRD}$ was reduced from 20.5 (3.8) $\mathrm{mm} \mathrm{Hg}$ to 10.6 (3.6) $\mathrm{mm} \mathrm{Hg}$ by octreotide in HAc treated rats. Response magnitude at all intensities tested was less without apparent effect on response threshold. There was no effect of octreotide on resting MAP in either group (saline treated 135.8 (3.3) mm Hg; HAc treated 134.2 (4.5) $\mathrm{mm} \mathrm{Hg}$ ).

When administered intrathecally, octreotide dose dependently attenuated both the visceromotor and pressor responses to CRD in saline treated rats (fig 2). Octreotide (10 and $15 \mu \mathrm{g}$ ) significantly decreased response magnitude and increased the VMR threshold. In HAc treated rats, octreotide evidenced little effect on the VMR and differences were not statistically significant. This likely reflects the visceral hyperalgesia produced by intracolonic instillation of HAc (see above and Burton and Gebhart $\left.{ }^{20}\right)$. Incomplete data were collected for the pressor response in HAc treated rats.

\section{SINGLE FIBRE STUDY}

A total of 15 afferent fibres in the decentralised S1 dorsal root, identified by electrical stimulation of the pelvic nerve and response to CRD, were studied. Ten fibres were myelinated $\mathrm{A} \delta$ fibres (mean conduction velocity 13.0 (1.9) $\mathrm{m} / \mathrm{s}$ ) and five fibres were unmyelinated $\mathrm{C}$ fibres (mean conduction velocity $2.0(0.2) \mathrm{m} / \mathrm{s}$ ). In the presence of the balloon in the descending colon, 11 fibres exhibited an ongoing discharge (mean 1.0 (0.3) imp/s; range 0.01-3.2). All 15 fibres were characterised for responses to graded intensities of CRD $(5-100 \mathrm{~mm} \mathrm{Hg})$ and all gave monotonic increases in response to increasing pressures of CRD which were temporally linked to stimulation. None gave on-off, rapidly adapting responses suggestive of mucosal afferent fibres. Cumulative intravascular administration of octreotide did not affect the responses to noxious CRD of any of 13 mechanosensitive pelvic nerve afferent fibres tested. Figure 3 illustrates examples of lack of effect of octreotide on responses of two different $\mathrm{A} \delta$ afferent fibres to $\mathrm{CRD}$ in uninflamed colon and zymosan inflamed colon. Note the enhanced response to CRD (that is, sensitisation) after intracolonic instillation of zymosan, which was unaffected by octreotide. Two fibres, in which octreotide did not attenuate responses to $\mathrm{CRD}$, were tested subsequently with U50,488, a kappa opioid receptor agonist. U50,488 attenuated responses to CRD (fig 3), as we have documented previously. ${ }^{22}$ 
Figure 4 summarises individual responses of fibres from untreated $(n=8)$ and HAc $(n=2)$ or zymosan $(n=3)$ treated colons in the presence of a broad range of cumulative doses of octreotide. There was no inhibition of responses of two afferent fibres to CRD when octreotide was given in doses of 50 and $100 \mu \mathrm{g} / \mathrm{kg}$ (data not shown).

\section{Discussion}

The present study has documented dose dependent antinociceptive effects of octreotide in a model of visceral nociception, but only when it was given into the intrathecal space. Systemic administration of octreotide was ineffective in attenuating either the visceromotor or pressor response to CRD in unanaesthetised rats. A previous study ${ }^{24}$ reported that the same dose of octreotide (100 $\mu \mathrm{g} / \mathrm{kg}$ intravenously) as used here markedly attenuated the depressor response to CRD in pentobarbitone anaesthetised rats. We tested for an effect of octreotide at the same time octreotide was reported by McKeen and colleagues ${ }^{24}$ to attenuate the response to CRD by about $80 \%$. They also reported that subsequent administration of octreotide $(100 \mu \mathrm{g} / \mathrm{kg}$ intravenously) was ineffective. In the cumulative intrathecal dosing paradigm we employed in some experiments however, the effect of octreotide was dose dependent and there was no apparent tachyphylaxis or desensitisation. It is not known why outcomes in these reports are discrepant. It may be that the distribution and concentration of octreotide in different peripheral and central compartments after its administration was inadequate. This seems unlikely however given that the same dose by the same route of administration was effective in the hands of others. ${ }^{24}$ It has been documented that anaesthesia affects responses to $\mathrm{CRD}^{18}$ and this may have contributed most to the differences in experimental outcomes reported.

Responses of pelvic nerve afferent fibres to noxious CRD were also unaffected by cumulative systemic doses of octreotide ranging from $0.5 \mu \mathrm{g} / \mathrm{kg}$ to $2.4 \mathrm{mg} / \mathrm{kg}$ in uninflamed acetic acid or zymosan inflamed colon. As a positive control, responses of two of the same fibres were attenuated by the kappa opioid receptor agonist U50,488. Accordingly, the mechanosensitive pelvic nerve fibres studied here, similar to those studied previously, ${ }^{22} 23$ are capable of modulation by drug actions in the periphery. If the modulatory effect of octreotide reported by McKeen and colleagues ${ }^{24}$ was due to a peripheral site of action, the wide range of doses tested here should have revealed an effect. Alternatively, peripheral effects of octreotide may be exerted at a site not studied here (for example, lumbar colonic, least splanchnic, or vagus nerves). The pelvic nerve innervation of the colon however is the most likely peripheral candidate site of action of octreotide for several reasons. When administered intrathecally at the spinal segments of pelvic nerve termination in the rat (L6-S1), octreotide dose dependently attenuated responses to CRD. Furthermore, when the pelvic nerve is transected, the visceromotor and pressor responses to CRD are virtually abolished (S Coutinho and GF Gebhart, unpublished observations). Possible effects of octreotide on vagal afferent input, which could conceivably activate descending modulatory systems in the brainstem in intact animals, would not be noted because pelvic nerve afferent fibres were recorded here in the decentralised S1 dorsal rootlet. Thus we interpret the present results to support a central, probably spinal, site of action of octreotide in this model of visceral nociception.

The analgesic effect of octreotide in human visceral pain occurs without affecting colonic tone or compliance. ${ }^{35}$ Plourde and colleagues ${ }^{2}$ and Chey and colleagues ${ }^{11}$ concluded that the analgesic effect of octreotide was produced at a peripheral site of action. Chey and colleagues ${ }^{11}$ compared cerebral and spinal evoked potentials produced by rectal stimulation before and after systemic administration of octreotide. They reported a $51 \%$ decrease in spinal evoked potentials and a 35\% decrease in cerebral evoked potentials by octreotide, concluding that the site of action of octreotide was on spinal afferents. In contrast, Johnston and colleagues $^{25}$ found that neither amplitude nor latency to any of three peaks of cortical evoked potentials produced by oesophageal balloon distension in healthy volunteers was affected by octreotide. Octreotide did however significantly increase the threshold volume to first sensation and the authors speculated on a peripheral site of action. Plourde and colleagues ${ }^{2}$ found that intrarectal injection of lidocaine blocked the increase in response threshold to slow tonic rectal distension produced by octreotide and concluded that the inhibitory effect of octreotide on rectal sensation could be either a peripheral effect on mucosal afferents or a spinal effect on dorsal horn neurones receiving converging input from mucosal and non-mucosal afferents. All pelvic nerve fibres studied here were muscle afferent fibres that responded to phasic colorectal distension; no mucosal afferent fibres were studied and we cannot rule out a peripheral mucosal site of action of octreotide. We consider this unlikely however because mechanosensitive mucosal receptors that respond to balloon distension are relatively few in number and rarely encode intensity of the stimulus.

The presence of somatostatin immunopositive cells in sensory dorsal root ganglia has been documented by several investigators (see Lawson ${ }^{26}$ for overview). Recent reports reveal that only small and intermediate sized perikarya are somatostatin immunoreactive, suggesting that somatostatin is associated with unmyelinated and thinly myelinated sensory axons (for example, see Hanesch and colleague ${ }^{27}$ ), many of which are likely nociceptors. Indeed, somatostatin is released in spinal cord following noxious peripheral stimulation. ${ }^{28}$ Interestingly, somatostatin immunopositive visceral afferents were not found in two studies $^{29}{ }^{30}$ but a more recent report documented the presence of somatostatin containing colon sensory neurones in the rat. ${ }^{31}$ In the 
spinal cord, somatostatin immunopositive fibres are found in significant numbers in the superficial dorsal horn, an area of termination of nociceptive afferent fibres. ${ }^{32}{ }^{33}$ Not all such fibre terminals however are of primary afferent origin and many terminals arise from somatostatin containing cells in the superficial dorsal horn. A significant number of spinal neurones in laminae I-III contain somatostatin but not GABA or glycine, suggesting they are not inhibitory spinal interneurones. ${ }^{34}$ Somatostatin receptors (SSTRs) have been localised in the periphery, including the gastrointestinal tract, and central nervous system. In the gastrointestinal tract, SSTRs are present in the mucosa of the stomach, small bowel, and colon, including in enterochromaffin-like cells in rat gastric mucosa and tumours in human colon. ${ }^{35-37}$ In inflamed human intestines, there is an increase in the expression of SSTRs, suggesting involvement in the pathophysiology of inflammatory bowel disorders. ${ }^{38}$ mRNAs for the five SSTRs were found to be widely distributed in the rat central nervous system as well as in visceral organs. ${ }^{39}$ SSTR2, at which octreotide binds with greatest affinity, was found to be widely distributed in the brain (highest in the amygdala, cortex, hypothalamus, and hippocampus), and principally the stomach and pancreas in the periphery.

The inability of systemic administration of a broad dose range of octreotide to attenuate responses of decentralised pelvic nerve afferent fibres to noxious CRD argues for a central site of action. This agrees with previous reports in models of cutaneous nociception. Betoin and colleagues $^{40}$ reported that vapreotide, an analogue of somatostatin, did not reduce carrageenan induced nociception when administered into the paw of rats but was effective when administered systemically (subcutaneous). They also reported vapreotide to be effective in the hot plate test in mice, a test considered to be sensitive only to centrally acting analgesics. In support, Chapman and Dickenson $^{41}$ found that intrathecally administered somatostatin analogues inhibited neurone responses to formalin injection into the hindpaw, whereas subcutaneous administration was effective only against the initial early response to formalin unless a substantially higher dosage was used (in which case both responses were affected), suggesting that the effects of the drug on the second phase are dependent on receptors in the central nervous system. Other authors have also examined the effects of somatostatin or its analogues on spinal nociceptive processing, reporting attenuation of responses of dorsal horn neurones to noxious stimuli. ${ }^{164243}$ Accordingly, there is ample evidence that somatostatin can affect dorsal horn neurones directly and the dose dependent antinociceptive effects of octreotide reported here, in a model of visceral nociception, suggest a central site of action of octreotide. In support, analgesic effects of somatostatin and its analogues have been demonstrated in humans and animals after intra thecal injection or spinal superfusion ${ }^{12-14} 1644-46$ and a recent report documented effects of somatostatin on cortical neurones. ${ }^{47}$ The present results are consistent with this interpretation that the reported effectiveness of octreotide in visceral pain arises at central sites of action.

The authors thank Mike Burcham for production of the graphics and Susan Birely for secretarial support. Supported by NIH award NS-19912. X Su was supported in part by an award from Pfizer Central Research, Sandwich, UK, and MB Burton was supported by T32 GMO7069.

1 Mayer EA, Gebhart GF. Basic and clinic aspects of visceral hyperalgesia. Gastroenterology 1994;107:271-93.

2 Plourde V, Lembo T, Shui Z, et al. Effects of the somatostatin analogue octreotide on rectal afferent nerves in humans. Am f Physiol 1993;265:G742-51.

3 Hasler WL, Soudah HC, Owyang C. A somatostatin analogue inhibits afferent pathways mediating perception of rectal distension. Gastroenterology 1993;104:1390-7.

4 Hasler WL, Soudah HC, Owyang C. Somatostatin analog inhibits afferent response to rectal distension in diarrheapredominant irritable bowel patients. F Pharmacol Exp Ther 1994;268:1206-11.

5 Bradette M, Delvaux M, Staumont G, et al. Octreotide Bradette $M$, Delvaux $M$, Staumont G, et al. Octreotide
increases thresholds of colonic visceral perception in IBS increases thresholds of colonic visceral perception in IBS patients withou $1171-8$.

6 Hökfelt T, Elde R, Johansson O, et al. Immunohistochemical evidence for separate populations of somatostatincontaining and substance P-containing primary afferent neurons in the rat. Neuroscience 1976;1:131-6.

7 Inagaki S, Kito S. Peptides in the peripheral nervous system. In Emson PC, Rossor MN, Tohyama M, eds. Progress in brain research, vol. 66. Amsterdam: Elsevier, 1986:269-316.

8 Señaris RM, Schindler M, Humphrey PPA, et al. Expression of somatostatin receptor $3 \mathrm{mRNA}$ in the motoneurones of the rat spinal cord, and the sensory neurones of the spinal ganglia. Mol Brain Res 1995;29:185-190.

9 Nakabayashi H, Kobayashi K, Nakabayashi IO, et al. Somatostatin receptor on the afferent nerve terminals in the rat hepatoportal area. Neurosci Lett 1995;183:46-9.

10 Heppelmann B, Pawlak M. Inhibitory effect of somatostatin on the mechanosensitivity of articular afferents in normal on the mechanosensitivity of articular afferents in normal

11 Chey WD, Beydoun A, Roberts DJ, et al. Octreotide reduces perception of rectal electrical stimulation by spinal afferent pathway inhibition. Am f Physiol 1995;269:G821-6.

12 Penn RD, Paice JA, Kroin JS. Octreotide: a potent new nonopiate analgesic for intrathecal infusion. Pain 1992;49:1319.

13 Paice JA, Penn RD, Kroin JS. Intrathecal octreotide for relief of intractable nonmalignant pain: 5-year experience with two cases. Neurosurgery 1996;38:203-7.

14 Chrubasik J, Meynadier J, Blond S, et al. Somatostatin: a potent analgesic. Lancet 1984;2:1208-9.

15 Krukoff TL, Ciiriello J, Calaresu FR. Somatostatin-like immunoreactivity in neurons, nerve terminals, and fibers of the cat spinal cord. 7 Comp Neurol 1986;253:13-22.

16 Sandkühler J, Fu QG, Helmchen C. Spinal somatostatin superfusion in vivo affects activity of cat nociceptive dorsal superfusion in vivo affects activity of cat nociceptive dorsal
horn neurons: comparison with spinal morphine. Neuroscience 1990;34:565-76.

17 Gebhart GF, Sengupta J N. Evaluation of visceral pain. In: Gaginella TS, ed. Handbook of methods in gastrointestinal pharmacology. Boca Raton, Florida: CRC Press, 1995:35973.

18 Ness TJ, Gebhart GF. Colorectal distension as a noxious visceral stimulus: physiologic and pharmacologic characterization of pseudaffective reflexes in the rat. Brain Res 1988;450:153-69.

19 Burton MB, Gebhart GF. Effects of kappa-opioid receptor agonists on responses to colorectal distension in rats with and without acute colonic inflammation. 7 Pharmocol Exp Ther 1998;285:707-15.

20 Burton MB, Gebhart GF. Effects of intracolonic acetic acid on responses to colorectal distension in the rat. Brain Res 1995;672:77-82

21 Coutinho SV, Su X, Sengupta JN, et al. Role of sensitized pelvic nerve afferents from the inflamed rat colon in the maintenance of visceral hyperalgesia. In: Sandkühler J, maintenance of visceral hyperalgesia. In: Sandkühler J,
Bromm B, Gebhart GF, eds. Nervous system plasticity and Bromm B, Gebhart GF, eds. Nervous system plasticity and chronic pain. Prog

22 Su X, Sengupta JN, Gebhart GF. Effects of kappa opioid receptor-selective agonists on responses of pelvic nerve afferents to noxious colorectal distension. $\mathcal{F}$ Neurophysiol 1997;78:1003-12.

23 Su X, Sengupta JN, Gebhart GF. Effects of opioids on mechanosensitive pelvic nerve afferent fibers innervating the urinary bladder of the rat. F Neurophysiol 1997;77: 1566-80.

24 McKeen E, Feniuk W, Humphrey PPA, et al. Inhibitory effect of octreotide and seglitide on vasodepressor responses induced by colonic distension in anaesthetized rats. Br f Pharmacol 1993;110:147.

rats. Br F Pharmacol 1993;110:147.
25 Johnston BT, Shils J, Leite LP, et al. Effects of octreotide on esophageal visceral perception and cerebral evoked potentials induced by balloon distension. Am $\mathcal{f}$ Gastroenterol 1999;94:65-70. 
26 Lawson SN. Morphological and biochemical cell types of sensory neurons. In: Scott SA. Sensory neurons. New York: Oxford University

27 Hanesch U, Heppelmann B, Schmidt RF. Somatostatin-like immunoreactivity in primary afferents of the medial articular nerve and colocalization with substance $\mathrm{P}$ in the cat. $\mathcal{F}$ Comp Neurol 1995;354:345-52.

28 Morton CR, Hutchison WD, Hendry IA, et al. Somatostatin: evidence for a role in thermal nociception. Brain Res 1989;488:89-96.

29 Molander C, Ygge J, Dalsgaard CJ. Substance P-, somatostatin- and calcitonin gene-related peptide-like immunoreactivity and fluoride resistant acid phosphataseactivity in relation to retrogradely labeled cutaneous, muscular and visceral primary sensory neurons in the rat. Neurosci Lett 1987;74:37-42.

30 Green T, Dockray GJ. Characterization of the peptidergic afferent innervation of the stomach in the rat, mouse and

31 Traub RJ, Hutchcroft K, Gebhart GF. The peptide content of colonic afferents decreases following colonic inflammaof colonic afferents decreases
tion. Peptides 1999;20:267-73.

32 Tuscherer MM, Seybold VS. A quantitative study of the coexistence of peptides in varicosities within the superficial laminae of the dorsal horn of the rat spinal cord. $f$ Neurosci 1989;9:195-205.

33 Ribeiro-da-Silva A, Cuello AC. Ultrastructural evidence for the occurrence of two distinct somatostatin-containing sy tems in the substantia gelatinosa of rat spinal cord. $\mathcal{F}$ Chem Neuroanat 1990;3:141-53.

34 Proudlock F, Spike RC, Todd AJ. Immunocytochemical study of somatostatin, neurotensin, GABA, and glycine in rat spinal dorsal horn. $\mathcal{F}$ Comp Neurol 1993;327:289-97.

35 Reubi JC, Laissue J, Waser B, et al. Expression of somatostatin receptors in normal, inflamed, and neoplastic human gastrointestinal tissues. Ann NY Acad Sci 1994;733:12237 .

36 Reubi JC, Horisberger U, Waser B, et al. High affinity somatostatin receptors in the human gut-associated lymphoid tissues; preferential location in germinal centers. Gastroenterology 1992:103:1207-14.

37 Radulovic SS, Milovanovic SR, Cai R-Z, et al. The binding of bombesin and somatostatin and their analogs to human colon cancers. Proc Soc Exp Biol Med 1992;200:394-401.

38 Reubi JC, Mazzucchelli L, Laissue JA. Intestinal vessels express a high density of somatostatin receptors in human inflammatory bowel disease. Gastroenterology 1994;106: 951-9.

39 Bruno JF, Xu Y, Song J, et al. Tissue distribution of somatostatin receptor subtype messenger ribonucleic acid in the rat. Endocrinology 1993;133:2561-7.

40 Betoin F, Herbet AA, Aumaitre HO, et al. Evidence for a central long-lasting antinociceptive effect of vapreotide, an analog of somatostatin, involving an opioidergic mechnism. F Pharmacol Exp Ther 1993;269:7-14.

41 Chapman V, Dickenson AH. The effects of sandostatin and somatostatin on nociceptive transmission in the dorsal horn of the rat spinal cord. Neuropeptides 1992;23:147-52.

42 Randic M, Miletic V. Depressant actions of methionineenkephalin and somatostatin in cat dorsal horn neurones activated by noxious stimuli. Brain Res 1978;152:196-202.

43 Murase K, Nedelikov V, Randic $M$. The actions of neuropeptides on dorsal horn neurons in the rat spinal cord
slice preparation:an intracellular study. Brain Res 1982; 234:170-6.

44 Leblanc R, Gauthier S, Gauvin M, et al. Neurobehavioral effects of intrathecal somatostatinergic treatment in subhuman primates. Neurology 1988;38:1887-90.

45 Mollenholt P, Post C, Rawal N, et al. Antinociceptive and neurotoxic actions of somatostatin in rat spinal cord after intrathecal administration. Pain 1988;32:95-105.

46 Gaumann DM, Yaksh TL, Post C, et al. Intrathecal somatostatin in cat and mouse: studies on pain, motor behaviour, and histopathology. Anesth Analg 1989;68:623-32.

47 Hicks GA, Feniuk W, Humphrey PP. Outward current produced by somatostatin (SRIF) in rat anterior cingulate pyramidal cells in vitro. Br f Pharmacol 1998;124:252-8. 